\title{
A comparative study of professional competence of nurses who have completed different bridging programmes
}

\author{
ZZ Nkosi, M Cur: Lecturer, University Of KwaZulu-Natal \\ LR Uys, D Soc Sc: Professor of Nursing, University of KwaZulu-Natal
}

\begin{abstract}
The aim of the study was to compare professional competence of nurses who completed different bridging programmes. Forty professional nurses from two different bridging programmes participated in the study. The newly qualified registered nurses were all from the province of Kwazulu- Natal working in various hospitals. The researcher utilized Slater Nursing Competencies Rating Scale. The instrument had the following categories (a) psychosocial (individual), psychosocial (group), (c) physical needs, (d) general, (e) communication and (f) professional implications.
\end{abstract}

The results showed that newly qualified nurses from different bridging programmes were professionally competent. Age, experience and examination results had no relationship with the professional competency of the newly qualified nurse.

\section{Problem statement}

Presently there are more than 35000 nurses in South Africa who wish to continue with their education and gain registration as a general nurse, since without the change of status they have no career path. There are few colleges which can train nurses, thus making the waiting lists very long. In order to bridge the gap between the professional nurses and the enrolled nurses, thebridging course was approved by the South African Nursing Council in 1989. (SANC, 1994).Most of the nurses registering for this programme are above the age of 25 years, married with many responsibilities. They have clinical experience as they have worked in the clinical situation for some time, but this experience was gained in a subservient role. Other sectors also find that continuing education is mandatory for ongoing competency (Christensen, 2004:921).

One wonders if the different types of curricula and teaching approaches produce similar results in learners that completed different bridging programmes. The problems of mature learners with work habits, family roles and ingrained learning behaviour has to be addressed by such curricula. If programme objectives are not achieved; these nurses may not function at the level expected of them as registered nurses.

\section{Aims and objectives}

The aim of this study was to compare the professional com- petency of bridging course students who studied via different programmes.

In order to achieve this aim the study seeked to address the following objectives:

- To compare competency levels of newly qualified nurses who studied the case based curriculum and those who studied the traditional curriculum

- To determine whether age, experience and examination results influence the professional competency of a newly qualified nurse.

According to Troskie (1993: 51) a competent nurse is a nurse who has completed her or his training and is able to perform nursing activities safely according to predetermined standards within the scope of practice, in coordination with other members of the health care team. In this study the competent nurse will be measured using the Slaters Rating Scale.

\section{Conceptual framework}

The researcher used Slater Rating Scale variables and Social learning theory by Bandura as a conceptual framework to describe the professional competency of nurses who studied through different bridging programmes. The Social learning theory of Bandura emphasizes the importance of observing and modeling the behaviours, attitudes and 


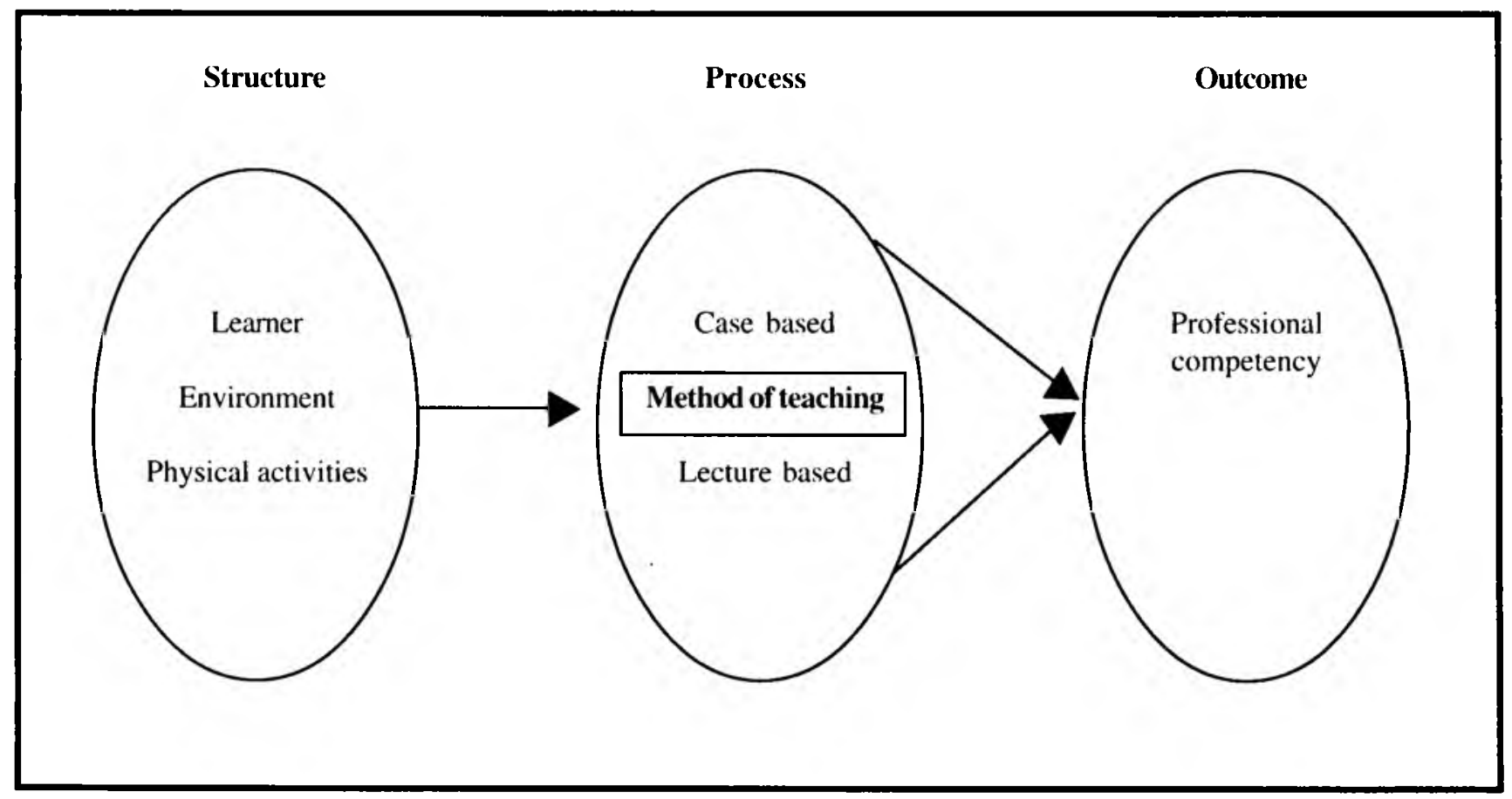

emotional reaction of others (Bandura, 1997). Social learning theory explains human behaviour in terms of continuous reciprocal interaction between cognitive and environmental influences.

\section{Literature review}

\section{Competency}

Several authors describe competency in a similar way. Searle and Pera (1992) and Quinn (1983:248) define competency as a demonstrated cognitive, affective and psychomotor ability required for the performance of specific activities.

Competency is based on comprehensiveness of an individual's knowledge and the ability to perform skills in an efficient and effective manner.Likewise Saylor (1990:11) describe reflective thinking as the artistry of combining professional repertoire with current clinical problems to invent unique responses. Saylor maintained that the ability to engage in reflective thinking is also essential for self evaluation and improving one's clinical competency.Society expects nurses to be professionally competent and emphatic givers (Duncan, 1996:45).

Rajanden (1995:90) linked competence to the qualifications, education or experience that is deemed necessary for acceptable performance of the job. Qualification is the essential formal training or study that a new employee would require if $\mathrm{s} / \mathrm{he}$ is able to perform a set job effectively. Experience is the minimum period of time necessary for an individual with the prescribed educational qualification to assume responsibility for the prescribed job and to perform it satisfactorily (Rajanden, 1995:98).

In order to evaluate the professional competency of an individual it is necessary to check on the clinical performance of the nurse. Maynard (1996:13) evaluated compe- tency using criterion-reference performance standards for students which clearly displayed the behaviour of an individual as dependent, assisted or independent.

Likewise Scheetz (1989:33) reported on the relationship between psychomotor skills and clinical competency. She concluded that the individuals who lack competency perform psychomotor skills awkwardly. Maynard (1996:13) and Nagelsmith (1985: 246) defined professional competency according to Benner (1984) as stages of skill acquisition whereby an individual can be a novice, advanced beginner, competent, proficient and expert .At this stage the individual lacks the speed and flexibility of the proficient nurse, but does have a feeling of mastery and ability to cope with many contingencies of clinical nursing (Maynard, $1996: 13$ ).

Competence goes beyond the performance of skills and acquisition of knowledge at or just above minimal levels of performance and cognitive standards, but also includes values, critical thinking, clinical judgment and integration of theory into the nursing roles (Nagelsmith, 1985: 246). The development of professional competence was

found to require a trio of abilities including cognitive, psychomotor and affective competencies initiated during the educational process. Acquisition of competence is initiated by education and developed through professional experience (Bloom, 1983).

According to Maynard (1996:15) the educational process must provide skills and knowledge upon which the learner can develop an educational base and service the opportunity and time development. Likewise Meretoja, Isoaho and Leiono-Kipli (2004: 124) reported that self assessment assist nurses to mantain and improve their competence which results in high levels of self confidence and professional competency. A similar view was expressed by Mulder (1992) 
when she defined clinical competence as the concept made up of knowledge, skills and affect, which are necessary for successful fulfillment of the professional nursing role.

Nurses need to acquire deep knowledge in order to master the skill in whatever action they perform. Status and legitimization are essential to crediting the knowledge embedded in the nursing practice. When the nurse's knowledge is taken seriously, patients benefit through having diagnostic and monitoring abilities of the nurses responded to appropriately (Benner and Wrubel, 1989). Skills need to be taught to those who are new graduates in the field of employment.

Nurse educators must share information about the skills to be learned for competency with student and the nursing service and they must teach and evaluate thoroughly those skills taught for competency .Joyce-Nagata, Reeb and Burch (1989: 316) reported on the importance of identifying specific nursing behaviours which reflect professional competency, because the actions of the nurse are strong indicators of competency.

Troskie (1993:53) recommended that the nurse's training background and age should be considered when placing those delegating responsibilities. They should receive the opportunity to develop their skills and become competent practitioners.

In summary therefore, apparently there is a relationship between, knowledge, attitude and skills whereby the learner acquires knowledge and the ability to perform skills. Unfortunately there were no previous comparative studies between the traditional and case based curricula.

\section{The case study approach}

The case study approach is a method with a long history, largely identified with law and business although it has been used in medical and nursing education. Since its installation in Harvard Law School in 1869, the case study method has gained popularity among educators in a variety of disciplines (Romm and Mahler, 1986).

Students are given a complete case for study and research in preparation for subsequent class discussion. The subsequent interactive case discussion in class, facilitated by the teacher in a tutor role combines both student- directed and teacher-directed learning. This method provides a stronger challenge to generate hypotheses, analyze data and make decisions with more active structuring of information in clinical content (Barrows, 1985). Therefore, the use of case base method encourages the learner to be Selfdirected. The advantages of a case method include its success in promoting theoretical understanding and insight, its strength in including motivation, psychological involvement and identification and its superiority over traditional techniques in encouraging self direction in learning (Romm \& Mahler, 1986). The conditions which enhance the successful implementation of case studies include the following:
- Careful choice of interesting, thought provoking cases by instructors;

- In-depth preparation of the case by the instructors and students prior to the discussion in class, and

- Flexibility and openness on the part of both the instructor and students during analysis of the cases in class (Romm \& Mahler, 1986).

\section{The lecture based method}

This teaching strategy allows the learner to be passive because the teacher is the active participant. The lecture based method of teaching is also know as the traditional approach because the learner is not involved in his/her teaching. The educator is the most active participant .There is little or no self direction from the student.Critiques of the traditional teaching approach highlighted poor problem solving skills and critical thinking skills as the major disadvantages (Romm \& Mahler, 1986).

\section{Methodology \\ Design}

The study was a comparative study and the design used was ex post facto because the research was conducted after the variations of the independent variable had occurred. The researcher compared the professional competency of graduates who studied via different curricula. Ex post facto is one of the broad classes of non-experimental research, in which the casual explanation are inferred after the fact (Polit\& Hungler, $1993: 436$ ). The independent variable was the teaching approach and the dependent variable was professional competence.

\section{Population and sample}

The target population consisted of newly qualified nurses within the twelve months of completion of the bridging course in Nursing Colleges and also at the University of KwaZulu-Natal. The King Edward College graduates were used in the study. The total numbers of graduates from both institutions were sixty eight (68). These graduates were in fifteen hospitals at the time of the study.

All graduates were included in the sample and proportional random sampling was done to ensure representitiveness. Students were given numbers and randomly selected from the list of students registered in both institutions. The total number sampled amounted to forty (40). The forty graduates sampled were scattered over eight hospitals in KwaZulu Natal. There were 38 females and two males. The hospitals were in rural and urban areas.

\section{Instrument}

The researcher used the instrument with two parts i.e. self designed demographic questionnaire and Slater Nursing Competencies Rating Scale (SRS) to conduct the study. SRS is a scale which consists of 84 items which identify actions performed by nursing personnel as they provide care to patients.

The standard of measurement is the quality of performance 
of care. The items are arranged into six subsections according to the primary science and cultural bases for the nursing care actions to be rated. Few items will be included from each subsection.

These subsections are as follows:

1. Psychosocial- Individual- Actions directed towards meeting psychosocial needs of individual patients.

- Gives full attention to patient

- Is a receptive listener

- Approaches patient in a kind, gentle and friendly manner

- Recognizes anxiety in patient and takes appropriate action

- Gives explanation and verbal reassurance when needed

- Responds in a therapeutic manner to patient's behaviour

2. Psychosocial group- Actions directed towards meeting psychosocial needs of members of the group.

- Conveys warmth and interest in group situations with patients

- Helps groups of patients accept necessary limits to freedom

- Encourages patients to participate in planning their own group living experiences

- $\quad$ Proposes activities appropriate to interests and needs of various patients within a group

- Delegates responsibility to patients according to their capabilities

- $\quad$ Shares time with all patients in a group

3. Physical- Actions directed towards meeting the physical needs.

- $\quad$ Adapts nursing procedures to meet needs of individual patients for daily hygiene and for treatment

- $\quad$ Attends to daily hygienic needs for cleanliness and acceptable appearance

- Utilizes nursing procedures as media for communication and interaction with patients

- Identifies physical symptoms and physical changes

- Recognizes physical distress and acts to provide relief for the patient

- $\quad$ Recognizes hazards to patient safety and takes appropriate action to maintain a safe environment

4. General- Actions that may be directed toward meeting either psychosocial or physical needs of patients or both at the same time.

- Utilizes patient teaching opportunities

- Involves patient and family in planning for care and treatment

- Protects sensitivities of patients

- Encourages patient to accept dependence/independence as appropriate to his condition
- Utilizes resources within a milieu to provide patient with opportunities for problem solving

- Responds appropriately to emergence situation

5. Communication- Communication on behalf of patients.

- Communicates ideas, facts, feelings and concepts clearly in speech.

- Communicates ideas, facts, feeling and concepts clearly in writing.

- Establishes a well-developed nursing care plan.

- Gives accurate reports, verbal and written, of patient's behaviour including behaviour that involved interaction with self.

- $\quad$ Participates freely in ward patient-care conferences

- Communicates effectively and establishes good relationships with other disciplines

6. Professional implications- Actions directed toward fulfilling responsibilities of a nurse in all facets and varieties of patients care situations

- Is self-directing: takes initiative and goes ahead on own

- Makes decisions willingly and appropriately

- Makes decisions that reflect both knowledge of facts and good judgment

- Gives verbal evidence of good insight into deeper problems and needs of patients

- Contributes as nurse member of health team to planning and evaluating care.

- $\quad$ Avails self of opportunities for learning.

The SRS was used by Troskie (1993:51) when she evaluated the competency of a newly qualified nurse who had completed the four year course. Also Fitzpatrick (1997:223) used it to measure clinical nurse performance.

\section{Validity and Reliability}

Content validity was obtained by using SRS which revealed an accurate picture of the newly qualified nurse in het or his work situation. The items on the Slater Rating Scale are similar to the Scope of Practice of a registered nurse in South Africa. Items on the scale have been examined extensively and repeatedly by nurse educators and nurse practitioners with expertise in all major areas (Wandelt \& Slater, 1975). One can therefore accept that the SRS has content validity.

\section{Data collection}

The registered nurses in charge of the units where newly qualified registered nurses worked completed the rating scale according to the performance of the nurse. The unit managers were briefed about the questionnaire before evaluating the newly qualified registered nurses. During the briefing sessions the unit managers were given documents which explained the yardstick against which observed nursing actions would be measured. 
The magnitude of the scale was the competence expected of a best nurse, average nurse and poor nurse. The unit managers were also given cue sheets which further explained actions of a nurse in detail. The participants filled in the demographic questionnaire this was later verified by the researcher because she had all the records from both institutions.

\section{Ethical consideration and confidentiality}

Written permission was granted by the Department of Health of KwaZulu Natal for research to be done in hospitals where newly qualified nurses were working. The Principal of King Edward College granted the researcher permission to check the records of previous bridging students who met the inclusion criteria. Written permission was sought from the registered nurses who did the bridging programme.

The whole questionnaire package (demographic and Slater Rating Scale) had an introductory letter which explained the aim of the research to the subjects. The letter also assured the respondents that anonymity and confidentiality would be maintained throughout the research. Willingness to participate was ensured by a consent letter and candidates were free to withdraw at any time of the study.Codes were used to identify nurses from different institutions since names were not allowed on the questionnaire.

\section{Results}

\section{Sample description}

There were forty (40) subjects from both training institutions, twenty (20) from King Edward College and twenty from The University of KwaZZulu Natal programme. All forty subjects were scattered in eight hospitals. The response rate was $100 \%$ since there were no missing cases. The age and experiences, as well as academic results of respondents are summarized in table 1 .

One of the most common non- parametrical statistical techniques (t-test) for determining the significance of differences between the means of two sets of data was used. Table 1 shows that there were no significant differences between the two groups in terms of demographic variables which could influence professional competency.

\section{Table 2: Professional competency of groups according to subcategories}

\begin{tabular}{|l|r|l|r|l|l|}
\hline Variable & \multicolumn{2}{|c|}{ Institute } & \multicolumn{2}{l|}{ KE College } & Difference of means \\
\hline & Mean & Std. Dev & Mean & Std.Dev & \\
\hline 1. Psychosocial(individual) & 4.100 & 0.8522 & 4.050 & 0.6863 & 0.500 \\
\hline 2.Psychosocial(group) & 4.100 & 0.6407 & 3.800 & 0.6959 & 0.300 \\
\hline 3.Physical needs & 4.300 & 0.5712 & 4.200 & 0.5231 & 0.100 \\
\hline 4.General & 4.050 & 0.7592 & 4.000 & 0.7255 & 0.500 \\
\hline 5.Communication & 4.350 & 0.6710 & 4.000 & 0.725 & 0.350 \\
\hline 6. Professional implications & 4.000 & 0.7255 & 4.050 & 0.3940 & 0.500 \\
\hline 7. Total & 25.00 & 3.179 & 24.00 & 2.895 & 0.800 \\
\hline
\end{tabular}


Table 3: Correlation between professional competence and other variables $(n=40)$

\begin{tabular}{|l|l|l|}
\hline & \multicolumn{2}{|l|}{ PROFESSIONALCOMPETENCE } \\
\hline & Correlation & Significance \\
\hline I. Age & 2.7 & 0.251 \\
\hline 2. Experience & 1.7 & 0.411 \\
\hline 3.Exam 1 & 3.2 & 0.2 \\
\hline 4. Exam2 & 2.8 & 0.359 \\
\hline
\end{tabular}

$\mathrm{Df}=2$

This is important, since a pre-test was not done to compare the professional competency of students before commencing the programmes.

\section{Competency rating}

The rating scale made use of a normative scale, with the best nurse $=5$, average nurse $=3$ and the below average nurse $=1$. In between best and average $=4$ and in between average and below average $r=2$. An average out of a possible 5 (best nurse) was calculated for each category, giving a total possible score of 30 for six categories.

The averages of the categories were calculated for each group and is reflected in table 2 .

From table 2 one can conclude that the mean difference was less than one on all subcategories. The mean score was close to 5 which were equal to the best nurse. In all the variables used, the scoring was above 4.00 . The degree of variability in the set of scores was less than one. The difference in the clinical competency between the groups was found not to be significant $(t=1.11, d f=38$ and $p=0.448)$. The nurses of both groups therefore showed that they were equally professionally competent. The question arises whether age, experience and test results were related, positively to clinical competence.

Association was done using the Pearsons as shown in the table 3 and the results were not significant. Therefore age, experience or academic performance cannot be related to professional competency.

When associating age, experience and examination results of the newly qualified nurses with the scores obtained on the Slater Rating Scale, the results were not significant. The researcher deduced that since the result were not significant on all variables used, there was no difference between the traditional and the case based curriculum. The $r$ value was above I $(r>1)$ which means that the demographic variables used had to relationship on the professional competence of a newly qualified nurse.

\section{Conclusion}

A total of 40 nurses from two groups were included in the sample to compare professional competence. The demographic variables used in the study were not related to professional competency. The newly qualified nurses from both programmes obtained high scores which determined the high quality performance of care. Since there is no significance difference between the two bridging programmes, both curricular and teaching programmes worked similarly in producing competent nurses.

\section{Limitations}

The following limitations were identified:

- The sample was a relatively small sample of forty participants and the results therefore are not generalizable

- The study focused only in KwaZulu- Natal and other provinces were not included.

\section{Recommendations for further research}

- $\quad$ Further research should be done to compare the clinical competence of incoming students to the bridging programme. This will help to act as a baseline for evaluation when they have completed the bridging programme.

- A comparison study between the newly qualified nurse who did the bridging programme and the nurse who did the comprehensive course should be done, in order to evaluate the product on completion of training.

- The research needs to be done on a larger scale and include other provinces so as to be more generalizable.

\section{Reference list}

BANDURA, A.1997: Self- efficacy: The exercise of control. New York: W.H.Freeman

BARROWS H.1985: How to design a problem based curriculum for the preclinical years. New York: Springers

BENNER P. \& WRUBEL J. 1989: Primacy of caring: Stress and coping in health and wellness. California: AddisonWesley Publishing Company

BENNER P. 1984: From novice to expert: Excellence and power in clinical nursing practice. Carlifornia: AddisonWesley

BLOOM B. 1956: Taxonomy of educational objectives. Handbook l Cognitive domain. New York: David Mckay Company

CHRISTENSEN G.J. 2004: Continuing Education: The 
good, the bad and the ugly. Journal of American Dental Association. 135(7):921-924

DUNCAN G.1996: An investigation of learning styles of practical and baccalaureate nursing students. Journal of Nursing Education. 35( 1): 40-42

FITZPATRICK, J.M.; WHILE, A.E. \& ROBERTS J.D. 1997: Measuring clinical nurse performance: development of the King's Nurse Performance Scale. International Journal of Nursing Studies. 34(3):223-229

KEEGAN D. 1986: The foundations of distance education. London: Croom Helm

KNOWLES M.S. 1984. Andragogy in action: Applying modern principles of adult learning. San Francisco: JosseyBass

MAYNARD A. 1996: Relationship of critical thinking ability to professional nursing competence. Journal of Nursing Education. 35(1): 199-203

MERETOJA, R; ISOAHO H. \& LEINO-KILPI H.2004. Nurse Competence Scale: development and psychometric testing.Journal of Advanced Nursing. 47 (2): 124- 133

MULDER M.1992: A Model for clinical evaluation. Curationis. 4: 16-20

JOYCE-NAGATA B., REEB R \& BURCH S.1989: Comparison of expected and evidenced Baccalaureate degree competencies. Journal of Nursing Education. 28(7): 31432]

NAGEISMITH L.1985: Competence: An evolving concept. Journal of Continuing Education in Nursing. 26(6): 245-248

QUINN F.M. 1983: Principles and practice of nursing education. London: Croom Helm

RAJANDREN R.1995: A case study of the application of Peromnes method of job evaluation to University of KwaZulu-Natal. Master's thesis: University of KwaZuluNatal

ROMM T. \& MAHLER S. 1986: A three dimensional model for using case studies in the academic classroom. Higher Education. 15: 677-696

SAYLOR C.R.1990. Reflection and professional education: art, science and competency. Nurse Educator 15:8-10

SCHEETZ L.J. 1989: Baccalaureate nursing student preceptor ship programme and development of clinical competence. Journal of Nursing Education. 28(1): 29-35

SEARI.E C. \& PERA S.1992: Professional practice: A South African perspective. Durban: Butterworths

SOUTHAFRICANNURSING COUNCIL:Terminology List.
50 Years. 1944-1994.Pretoria

TROSKIE R 1993: Critical evaluation of the newly qualified nurse's competency to practice. Curationis. 16 (3): 50 55

WANDELT A.W. \& STEWART D .1975: Slater nursing competencies rating scale. New York: Appleton- Century Croft. 